\title{
Enthalpy of isopropanol adsorption on zeolite
}

\author{
Maciej Jabłoński ${ }^{1}$, Alicja Dzienisz ${ }^{1}$, Marta Sawicka ${ }^{1}$, Elwira Wróblewska ${ }^{1}$, Krzysztof Lubkowski ${ }^{1}$, \\ Grażyna Dąbrowska², Mateusz Piz ${ }^{2}$, Joanna Sreńscek-Nazzal ${ }^{3}$
}

\author{
West Pomeranian University of Technology, Faculty of Chemical Technology and Engineering, Al. Piastów 42, 71-065 \\ Szczecin, Poland \\ ${ }^{1}$ Department of Organic and Physical Chemistry \\ ${ }^{2}$ Department of Inorganic and Analytical Chemistry \\ ${ }^{3}$ Institute of Chemical and Environment Engineering \\ "Corresponding author: e-mail: Alicja.Soltys@zut.edu.pl
}

\begin{abstract}
The enthalpy of isopropanol adsorption on ZSM-5 (Zeolite Socony Mobil Framework Type MFI) was determined by the static adsorption method at the temperature range from $20^{\circ} \mathrm{C}$ to $100^{\circ} \mathrm{C}$. Langmuir and Huttig models of equilibrium adsorption have been used to calculate the enthalpy of isopropanol adsorption at these conditions. Adsorption isotherms determined by the flow method at $20^{\circ} \mathrm{C}$ and $30^{\circ} \mathrm{C}$ have been also used in the calculations. The obtained values of isopropanol adsorption enthalpy were compared with the values of isopropanol evaporation enthalpy and with the results obtained from isopropanol and water desorption measurements with thermogravimetry and differential scanning calorimetry methods.
\end{abstract}

Keywords: Enthalpy, Adsorption, Zeolite, HiSiv 3000, Isopropanol.

\section{INTRODUCTION}

The heat of adsorption is related to the force with which the adsorbate molecules are attached to the active surface. From the isotherms measurements at different temperatures, a series of isosteres can be generated and then, taking into account the slopes of these isosteres, the heat of adsorption is calculated. It is generally accepted to present the heat of adsorption as a function of the adsorbate amount. In most cases, absolute adsorption heat values decrease with adsorbate amount, demonstrating the energetically heterogeneous adsorbent surface. On the other hand, constant heat of adsorption indicates the existence of a homogeneous surface.

A basic understanding the great chemical diversity that occurs on surfaces requires knowledge of the interaction between particles and the surface. Two main types of adsorption can be distinguished. The first one is relatively weak and it is called physical adsorption (physisorption). The physical equilibrium of adsorption is usually established very quickly, except in cases limited by gas diffusion. The second type of adsorption has a much stronger character. When the molecules are attached to the surface, chemical bonds can be formed between the adsorbed molecule and the surface in the process of so-called chemisorption ${ }^{1}$. The heat of adsorption is related to the force with which the adsorbate molecules are bound to the active surface.

Thermodynamically, enthalpy of adsorption is the heat released or absorbed during the adsorption process. In the majority of cases, adsorption is an exothermic process. The heat of adsorption depends on the amount of adsorbed substance, but also on the type of interaction between the adsorbed substance and the adsorbent surface ${ }^{2}$.

Activated carbon is widely used as an adsorbent. It is relatively inexpensive but has many disadvantages such as fire risk, clogging of pores, hygroscopicity, and regeneration problems. For these reasons, in recent years a great effort has been made to find an alternative to activated carbon adsorbents. Of the optional adsorbents, special attention is paid to zeolite adsorbents. These adsorbents have proved to be useful for adsorbing volatile organic compounds (VOC's); they are stable at elevated temperatures and retain good adsorption properties for wet gas purification. They are also not flammable.

This paper presents the results of isopropanol adsorption on zeolite and an estimation of the heat of adsorption. The enthalpy of isopropanol adsorption $\left(\Delta \mathrm{H}_{\mathrm{ad}}\right)$ on zeolite was determined on the basis of the isotherms obtained at temperatures from $20^{\circ} \mathrm{C}$ to $100^{\circ} \mathrm{C}$ by static adsorption $^{3}$. Langmuir and Huttig models of equilibrium adsorption were used to calculate $\Delta \mathrm{H}_{\mathrm{ad}}$. As far as we know, the investigations on isopropanol adsorption were presented in very few papers, including adsorption on various carbon adsorbents, ${ }^{4,5}$, different types of zeolites ${ }^{6,7}$ or a combination of zeolite and carbon adsorbents ${ }^{8}$. However, none of them used the Huttig model for calculations. Adsorption isotherms determined by the flow method at $20^{\circ} \mathrm{C}$ and $30^{\circ} \mathrm{C}$ were also used in the calculations. The obtained $\Delta \mathrm{H}_{\mathrm{ad}}$ values were compared with the values of isopropanol evaporation enthalpy and with the results of isopropanol and water desorption obtained in thermogravimetric and differential scanning calorimetry (DSC) measurements.

\section{EXPERIMENTAL}

\section{Materials and methods}

HiSiv 3000 zeolite (UOP LLC, USA) was used as the adsorbent in the adsorption investigations. HiSiv 3000 adsorbent is an organophilic high-silica molecular sieve (also referred to as high silica zeolite) with a pore structure enabling adsorption of molecules with critical diameters up to $0.6 \mathrm{~nm}$. HiSiv adsorbents are hydrophobic and selective for organics in the presence of water. HiSiv adsorbents are not flammable and non-reactive with most chemicals ${ }^{9}$. The specific surface area of HiSiv 3000, determined by the BET method, was 375 $\mathrm{m}^{2} / \mathrm{g}^{10}$, while other parameters of HiSiv 3000 were given previously ${ }^{9-12}$. 
Isopropanol was selected for investigation of adsorption on zeolite as one of many representatives of compounds belonging to the group of volatile organic compounds (VOC). Isopropanol of analytical purity $98 \%$ (PPH POCh, Gliwice, Poland) was used as the adsorbate. The boiling point of isopropanol is $355.5 \mathrm{~K}$, while the vapour pressure at $298 \mathrm{~K}$ is $4451 \mathrm{~Pa}^{\mathbf{1 3}}$. It is a polar protic solvent, colourless liquid with a strong, characteristic odour.

\section{Adsorption experiments}

Isopropanol adsorption and desorption on HiSiv 3000 zeolite were carried out on the home-made adsorption installation using the flow method (Figure 1). Measurements were carried out at $20^{\circ} \mathrm{C}$ and $30^{\circ} \mathrm{C}$. The installation was not hermetically isolated, therefore measurements at higher temperatures were not possible. As an inert gas we used air with a volumetric flow rate of $71.44 \mathrm{dm}^{3} / \mathrm{h}$. Air is a relatively cheap gas and it is also used as an inert gas in technological processes. The air was flowing through the column filled with silica gel and the column filled with activated carbon. The air was divided into two streams. One of them passed through the thermostated saturator filled with isopropanol and then was directed to the mixer to join the second stream. From the mixer, the gas was flowing through the thermostated column filled with the adsorbent, where the adsorption isotherms of isopropanol were determined. The measurements were carried out until a constant HiSiv 3000 zeolite mass was obtained. The adsorption isotherms of isopropanol on zeolite were investigated in the range of relative pressure $\mathrm{p} / \mathrm{p}^{0}$ from 0.04 to 1 , where $\mathrm{p}$ is the current pressure and $\mathrm{p}^{0}$ is the saturated vapour pressure. The measurements were repeated three times and the result were averaged.

\section{RESULTS AND DISCUSSION}

The interaction of the adsorbed substance with the adsorbent can be described using chemical equations.
We can present the adsorption process in the form of the following equation:

$\mathrm{A}+\mathrm{S} \leftrightarrow \mathrm{AS}$

where: $\mathrm{A}$ is the adsorbed substance, while $\mathrm{S}$ is the adsorbent surface.

If the total surface of the adsorbent is covered with a monolayer of adsorbed substance, then the current concentration of AS can be presented as a fraction of occupied surface $\mathrm{x}_{\mathrm{s}}$. Therefore, a fraction of available surface will be $1-\mathrm{x}_{\mathrm{s}}$.

At equilibrium, we can write the equation for the equilibrium constant:

$\mathrm{K}=\mathrm{x}_{\mathrm{s}} /\left[\left(1-\mathrm{x}_{\mathrm{S}}\right) \cdot \mathrm{p}_{\mathrm{A}}\right]$

where: $\mathrm{p}_{\mathrm{A}}$ corresponds to the partial pressure, while $\mathrm{x}_{\mathrm{s}}$ is a fraction of occupied area

The value of $\mathrm{x}_{\mathrm{s}}$ can be determined from the equation: $\mathrm{x}_{\mathrm{s}}=\mathrm{q} / \mathrm{q}_{\mathrm{m}}$

where: $\mathrm{q}_{\mathrm{m}}$ corresponds to the maximum amount of adsorbed substance, whereas q corresponds to the actual amount adsorbed.

Using equations (2) and (3) after transformations, we obtain the equation, which is the Langmuir equation:

$\mathrm{q}=\mathrm{q}_{\mathrm{m}} \cdot \mathrm{K} \cdot \mathrm{p}_{\mathrm{A}} /\left(1+\mathrm{K} \cdot \mathrm{p}_{\mathrm{A}}\right)$

The reaction equilibrium constant is a function of temperature. This relationship is described by the equation:

$\left(\frac{\partial \ln \mathrm{K}}{\partial \mathrm{T}}\right)_{\mathrm{p}}=\frac{\Delta \mathrm{H}_{\mathrm{ad}}^{0}}{\mathrm{RT}^{2}}$

This equation can be used to determine the enthalpy or internal energy of adsorption, which, depending on the reaction conditions, will be related to the heat of adsorption. Assuming the independence of the adsorption enthalpy $\Delta \mathrm{H}_{\mathrm{ad}}$ from the temperature in a small $\Delta \mathrm{T}$ interval, we can determine this parameter from the Langmuir equation (4). The adsorption enthalpy determined in this way is related to the monolayer adsorption model.

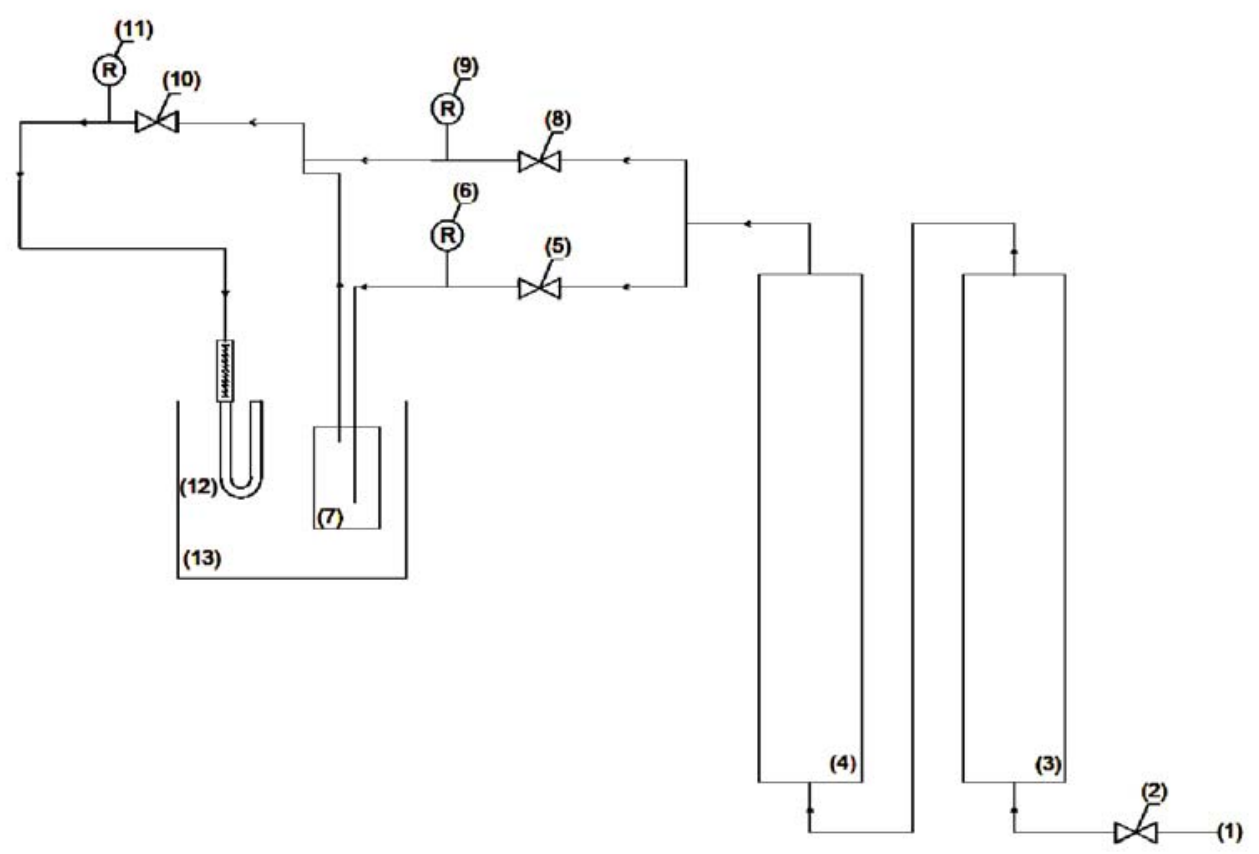

Figure 1. Diagram of flow adsorption installation: (1) - air inlet, (2), (5), (8), (10) - valves, (3) - column filled with silica gel, (4) - column filled with activated carbon, (6), (9), (11) - rotameters, (7) - scrubber, (12) - adsorbent container, (13) thermostat. 
In the case of a multi-layer adsorption model, the calculation of the enthalpy of adsorption requires the adoption of an appropriate model. In this case, in addition to reaction (1), it can be assumed that the following reactions will take place:

$\mathrm{AS}+\mathrm{A} \leftrightarrow \mathrm{AAS}$

$\mathrm{AAS}+\mathrm{A} \leftrightarrow \mathrm{AAAS}$

Similarly, we can write successive equations for subsequent layers. For each of these reactions, equilibrium constant can be determined and similar considerations can be made as in the first case. In the case of subsequent layers of the adsorbent, it can be assumed that the heat of adsorption of subsequent layers, with the exception of the first one, is the same. On the basis of the assumptions and transformations, we obtain the equation:

$\mathrm{q}=\mathrm{q}_{\mathrm{m}} \cdot \mathrm{K}_{1} \cdot \mathrm{p}_{\mathrm{A}}\left(1+\mathrm{K}_{2} \cdot \mathrm{p}_{\mathrm{A}}\right) /\left(1+\mathrm{K}_{1} \cdot \mathrm{p}_{\mathrm{A}}\right)$

where: $K_{1}$ is the equilibrium constant for the reaction (1), while the $\mathrm{K}_{2}$ parameter refers to the subsequent layers of the adsorbent.

The obtained equation (8) is called the Huttig equation $^{\mathbf{1 4}}$. This adsorption model can be used also to determine the heat of adsorption.

Both models (Langmuir and Huttig) were used to calculate the heat of adsorption. The results of isothermal adsorption of isopropanol on zeolite, determined by the static method in the temperature range from $20^{\circ} \mathrm{C}$ to $100^{\circ} \mathrm{C}^{\mathbf{8}}$, were used as experimental data. Adsorption isotherms obtained on the basis of these results are presented in Figure 2.

For each of the above isotherms, the constant $\mathrm{K}$ in the Langmuir equation was determined by the Marquardt and linearization methods. Using equation (5), the value of $\Delta \mathrm{H}_{\mathrm{ad}}$ was also determined. The results are summarized in Table 1 and in Figure 3.

Differences in the results of calculations obtained by the linearization method and the Marquardt method

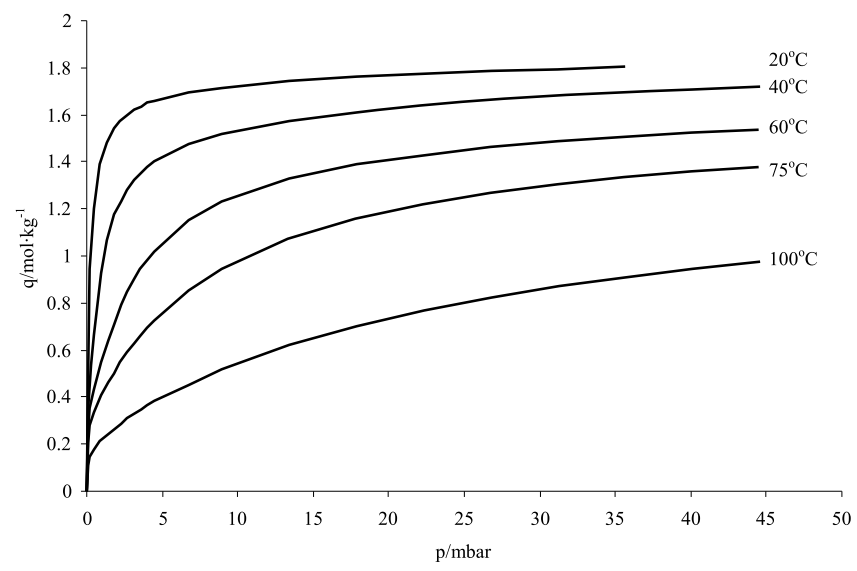

Figure 2. Isotherms of isopropanol adsorption on HiSiv 3000 zeolite measured with the static method ${ }^{8}$

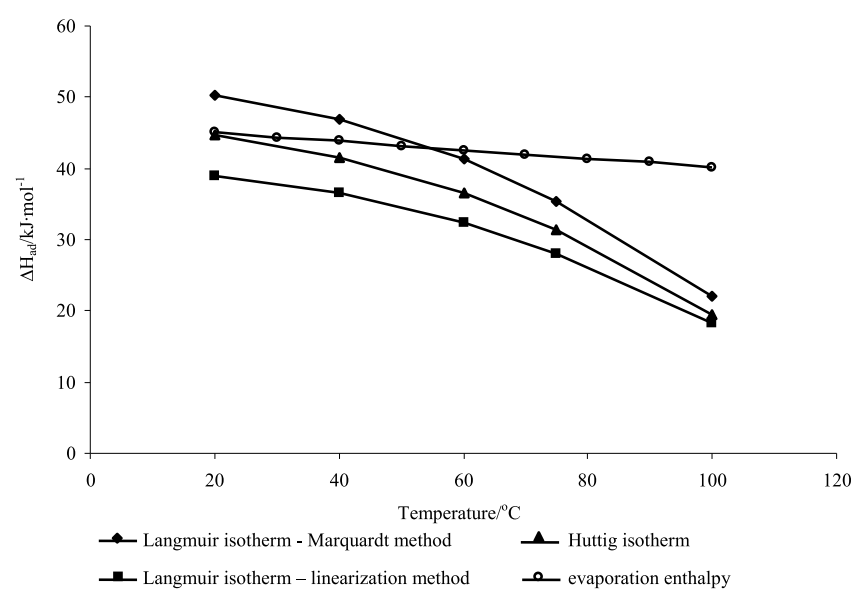

Figure 3. Dependence of the heat of adsorption on temperature calculated by the Marquardt and linearization methods based on Langmuir and Huttig model, in comparison with the enthalpy of evaporation

are associated with the so-called transformation errors. As a criterion for the selection of the calculation method, the level of correlations of calculated values with experimental values was used. In this case, a better fit is obtained when using the Marquardt method.

Similar calculations of the adsorption enthalpy as for the Langmuir model were made using the Huttig multi-layer adsorption model. The results of these calculations are also presented in Figure 3 showing the dependence of adsorption heat on temperature. The obtained results were compared to the heat of isopropanol evaporation. The graph shows large differences in obtained adsorption heat values depending on the calculation method, up to $25 \%$ in the case of the Langmuir model. In the case of the Huttig model, only the Marquardt method was used in the calculations. Obtained results of calculations are approximately an average of the results from the Langmuir model and in the initial temperature range are similar to the heat of evaporation.

\section{Characterization of the adsorbent}

The textural characterization of HiSiv 3000 zeolite was carried out by $\mathrm{N}_{2}$ adsorption-desorption isotherm measurements at $77 \mathrm{~K}$ on a Quadrasorb evo sorptiometer (Quantachrome Instruments, USA). Prior to analysis, samples were degassed at $293.15 \mathrm{~K}$ for $4 \mathrm{~h}$. The specific surface area (SBET) was calculated using the BrunauerEmmett-Teller (BET) equation. The value of specific area calculated on the basis of nitrogen adsorption isotherm differs from the value presented in the papers ${ }^{\mathbf{1 0}}$. The total pore volumes were evaluated on the basis of the volume adsorbed at a relative pressure of about 0.99 . Textural parameters of HiSiv 3000 zeolite obtained with BET method are presented in Table 2. The $\mathrm{N}_{2}$ adsorption/ desorption isotherm of the zeolite sample is presented

Table 1. Isopropanol adsorption on HiSiv 3000 zeolite - enthalpy calculations

\begin{tabular}{|c|c|c|c|c|c|c|}
\hline & \multicolumn{3}{|c|}{$\begin{array}{c}\text { Marquart } \\
\text { method }\end{array}$} & \multicolumn{3}{c|}{$\begin{array}{c}\text { Linearization } \\
\text { method }\end{array}$} \\
\hline $\begin{array}{r}\text { Temp } \\
\left.{ }^{\circ} \mathrm{C}\right]\end{array}$ & $\begin{array}{c}\mathrm{K} \\
{[-]}\end{array}$ & $\begin{array}{c}\Delta \mathrm{H} \\
{\left[\mathrm{kJ} \cdot \mathrm{mol}^{-1}\right]}\end{array}$ & $\mathrm{R}^{2}$ & $\begin{array}{c}\mathrm{K} \\
{[-]}\end{array}$ & $\begin{array}{c}\left.\Delta \mathrm{H} \cdot \mathrm{mol}^{-1}\right] \\
\mathrm{R}^{2}\end{array}$ \\
\hline 20 & 4.872 & -50.27 & 0.9846 & 2.920 & -38.86 & 0.9313 \\
\hline 40 & 1.348 & -46.90 & 0.9710 & 1.061 & -36.47 & 0.9609 \\
\hline 60 & 0.484 & -41.25 & 0.9635 & 0.494 & -32.38 & 0.9603 \\
\hline 75 & 0.270 & -35.35 & 0.9902 & 0.300 & -28.07 & 0.8155 \\
\hline 100 & 0.136 & -22.05 & 0.9900 & 0.175 & -18.29 & 0.8319 \\
\hline
\end{tabular}


Table 2. Textural parameters of HiSiv 3000 zeolite

\begin{tabular}{|l|c|c|}
\hline Sample & $\mathrm{S}_{\mathrm{BET}}\left[\mathrm{m}^{2} \cdot \mathrm{g}^{-1}\right]$ & $\mathrm{V}_{\text {total }}\left[\mathrm{cm}^{3} \cdot \mathrm{g}^{-1}\right]$ \\
\hline HiSiv 3000 zeolit & 298 & 0,2286 \\
\hline
\end{tabular}

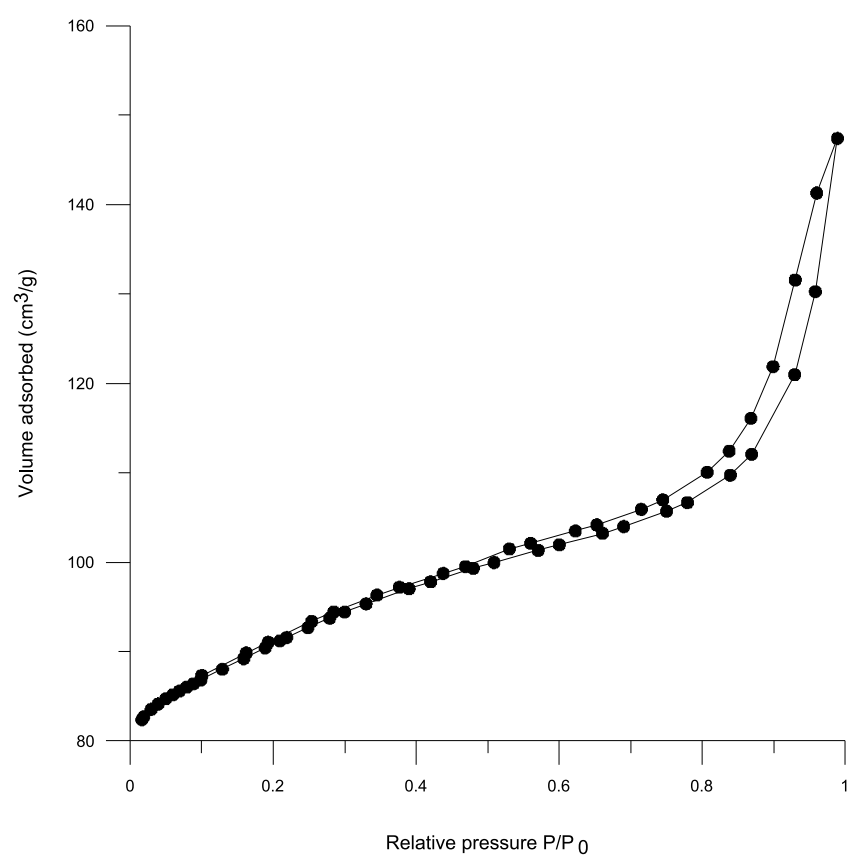

Figure 4. $\mathrm{N}_{2}$ adsorption/desorption isotherms on HiSiv 3000 zeolite

in Figure 4. The isotherm is of I type characteristic for microporous materials defined by IUPAC. The hysteresis observed for $\mathrm{P} / \mathrm{P}_{0}>0.5$, which is associated with the pore condensation phenomena, indicates the mesopores presence as well.

Based on the $\mathrm{N}_{2}$ adsorption/desorption isotherm at $77 \mathrm{~K}$, the pore size distribution was determined and shown in Figure 5. The pore size distribution was determined using the density functional theory (DFT).

The chemical composition of HiSiv 3000 zeolite was determined by the fluorescence X-ray spectrometer XRF

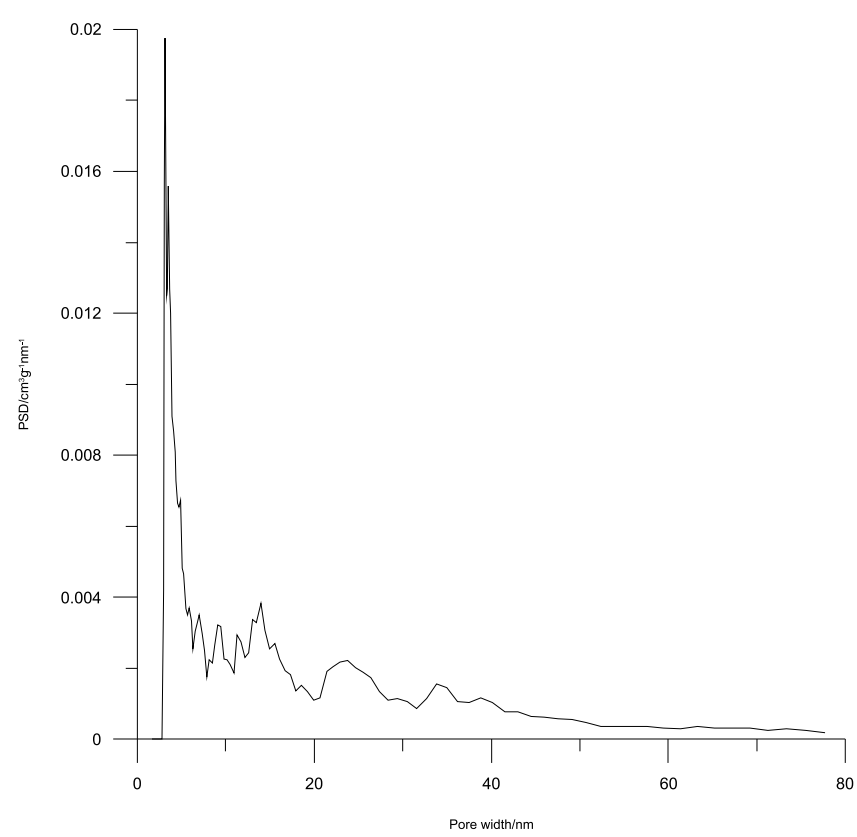

Figure 5. The pore size distribution of HiSiv 3000 zeolite calculated from $\mathrm{N}_{2}$ adsorption/desorption isotherms at $77 \mathrm{~K}$
Philips PW 1480 (Table 3). The main elements of this zeolite are $\mathrm{SiO}_{2}$ and $\mathrm{MgO}$. On the basis of the analysis results it can be concluded that HiSiv 3000 zeolite belongs to the group of dealuminated adsorbents, which are characterized with a very small ratio of $\mathrm{Al}_{2} \mathrm{O}_{3}$ to $\mathrm{SiO}_{2}$.

Table 3. Chemical composition of HiSiv 3000 zeolite

\begin{tabular}{|l|c|c|c|c|c|c|c|}
\hline \multicolumn{7}{|c|}{ Chemical composition, \% } \\
\hline $\mathrm{SiO}_{2}$ & $\mathrm{Al}_{2} \mathrm{O}_{3}$ & $\mathrm{MgO}$ & $\begin{array}{l}\mathrm{Na}_{2} \\
\mathrm{O}\end{array}$ & $\begin{array}{l}\mathrm{Fe}_{2} \\
\mathrm{O}_{3}\end{array}$ & $\mathrm{CaO}$ & $\mathrm{K}_{2} \mathrm{O}$ & $\mathrm{TiO}_{2}$ \\
\hline 72.8 & 0.62 & 15.0 & 4.8 & 3.1 & 2.0 & 0.82 & 0.45 \\
\hline
\end{tabular}

The XRD diffractometer Empyrean II (PANalytical, The Netherlands) equipped with the X-ray tube with the copper anode was used to investigate the phase composition of zeolite. The measurement result of samples at different temperatures is presented in Figure 6.

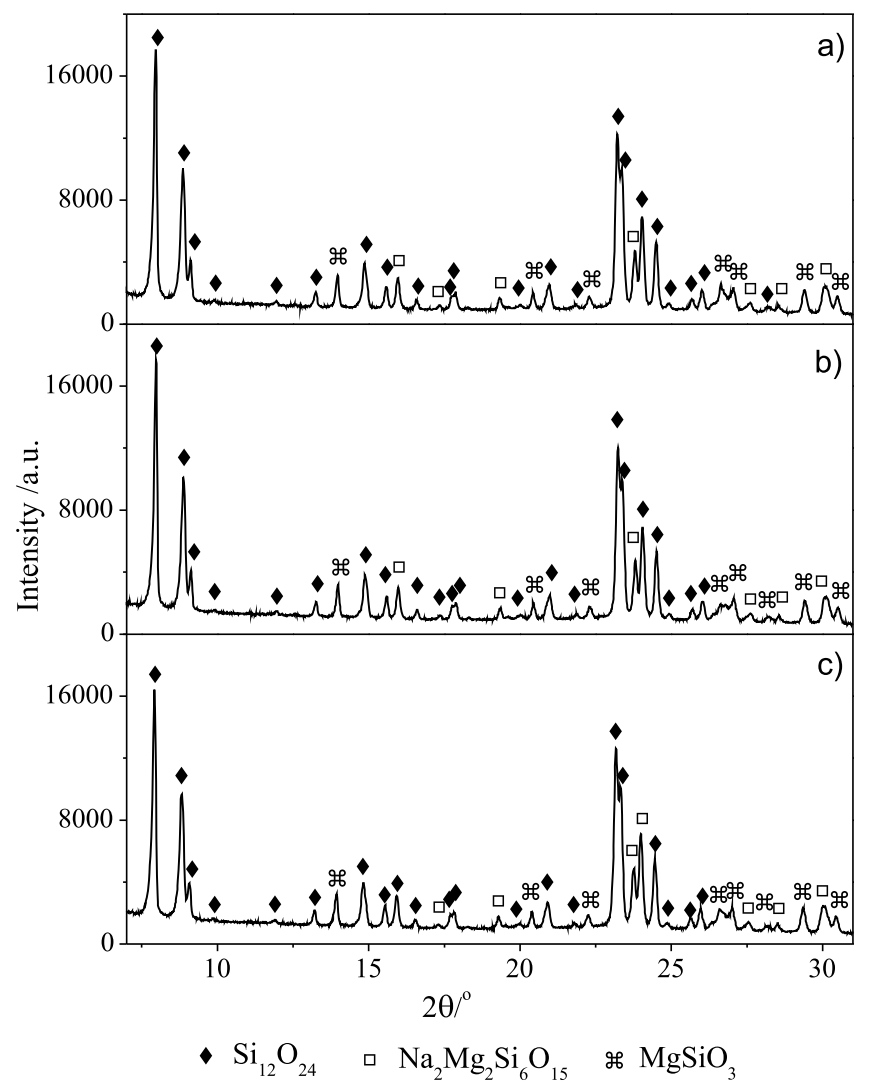

Figure 6. Diffraction patterns of HiSiv 3000 zeolite: a) without heating, b) after heating at $250^{\circ} \mathrm{C}, \mathrm{c}$ ) after heating at $500^{\circ} \mathrm{C}$

The obtained results indicate that the zeolite structure does not change with temperature up to $500^{\circ} \mathrm{C}$. Characteristic lines of $\mathrm{Si}_{12} \mathrm{O}_{24}, \mathrm{MgSiO}_{3}$ and $\mathrm{Na}_{2} \mathrm{Mg}_{2} \mathrm{Si}_{6} \mathrm{O}_{15}$ can be seen on the diffractogram. Before the investigation of adsorption of the selected VOC, zeolite was heated at $250^{\circ} \mathrm{C}$ in air atmosphere for 4 hours. This was to remove any organic impurities and water that could be present in the pores of the adsorbent.

\section{Adsorption study}

The zeolite samples saturated with isopropanol were investigated by using the thermogravimetry on a MOM $1500 \mathrm{C}$ thermogravimeter (MOM, Hungary) and differential scanning calorimetry on a DSC 2010 calorimeter (TA Instruments, USA). During the thermogravimetry test, approximately $40 \mathrm{mg}$ of samples were heated in 
air atmosphere. The DSC measurement consisted of heating 15-24 mg sample under nitrogen atmosphere. The sample heating rate was $2 \mathrm{~K} / \mathrm{min}$ in both cases. The measurement was carried out at temperatures ranging up to $600^{\circ} \mathrm{C}$.

The isotherms of isopropanol adsorption on HiSiv 3000 zeolite were determined using the flow method at temperatures of $20^{\circ} \mathrm{C}$ and $30^{\circ} \mathrm{C}$. Obtained results are presented in Figure 7 and Figure 8. As can be seen in Figure 7, in the first part of the isotherm, with an increase in concentration, adsorption increases quite rapidly. On the other hand, in the second part of the isotherm, the level of adsorption changes slightly with a further increase in adsorbate concentration. In the last part of the isotherm, the adsorption increases again faster, up to the maximum saturation pressure of isopropanol at $20^{\circ} \mathrm{C} 51.02$ mbar and $30^{\circ} \mathrm{C} 91.25$ mbar respectively. The shape of isotherms at $20^{\circ} \mathrm{C}$ and $30^{\circ} \mathrm{C}$ is the same, but there are differences in the range of equilibrium pressures and lower adsorption values for isotherm determined at $30^{\circ} \mathrm{C}$.

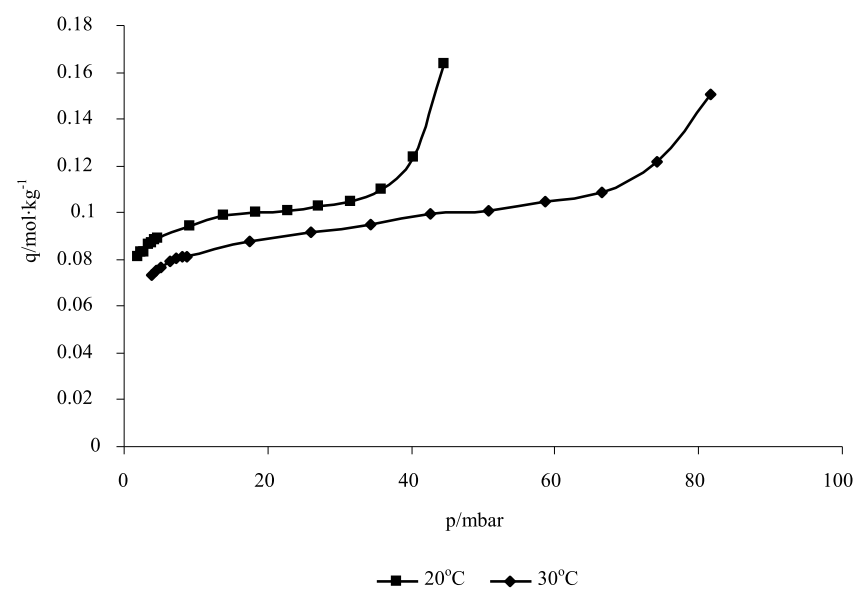

Figure 7. Isotherms of isopropanol adsorption on HiSiv 3000 zeolite at temperatures of $20^{\circ} \mathrm{C}$ and $30^{\circ} \mathrm{C}$, obtained by the flow method

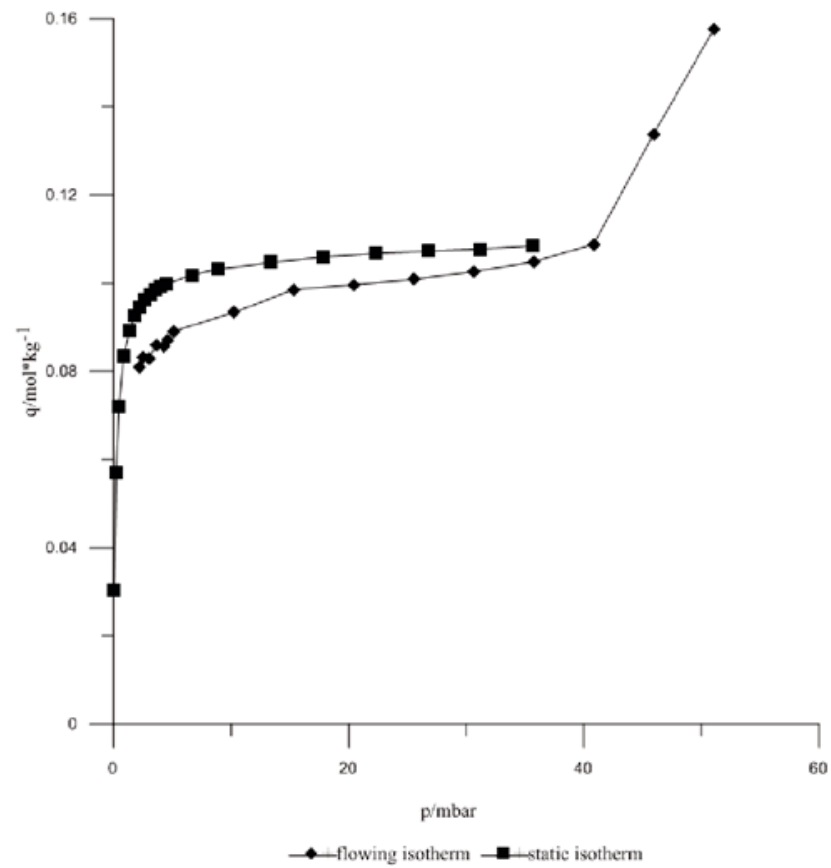

Figure 8. Comparison of isopropanol adsorption isotherms on HiSiv 3000 zeolite at $20^{\circ} \mathrm{C}$, obtained by the static and flow methods
Figure 8 presents the results of adsorption isotherms investigated by the static and flow methods. From the comparison of the isotherms shown in Figure 7 it follows that the shape of the adsorption isotherm investigated by the static method is very similar to the classic Langmuir isotherm. In the case of adsorption isotherm investigated by the flow method, the shape of the first part of the isotherm is similar to the isotherm investigated by the static method. The isotherm investigated by the flow method shows slightly lower adsorption values. The main difference in shape is visible in the last part of the isotherm, where a rapid increase in adsorption occurs. The shape of the last part of the isotherm may indicate the phenomenon of capillary condensation.

Based on the obtained adsorption isotherms determined by the flow method, adsorption enthalpies were calculated using the Langmuir and Huttig models. In the case of the Langmuir model, the calculated adsorption enthalpy was $70.1 \mathrm{~kJ} / \mathrm{mol}$, while in the case of the Huttig model the adsorption enthalpy was $43.0 \mathrm{~kJ} / \mathrm{mol}$.

The calculated value of adsorption enthalpy obtained on the basis of the Langmuir model definitely differs from the value calculated on the basis of isotherms determined by the static method. However, in the case of the Huttig model, the determined value of adsorption enthalpy is close to the value of adsorption enthalpy calculated on the basis of isotherms determined by the static method.

The obtained results of adsorption enthalpy calculations were compared with the results of desorption heat determined by thermogravimetry (TG) and differential scanning calorimetry (DSC) methods. These methods of investigation were used for the first time for pure zeolite. The results of the investigation are presented in Figure 9 and Figure 10.

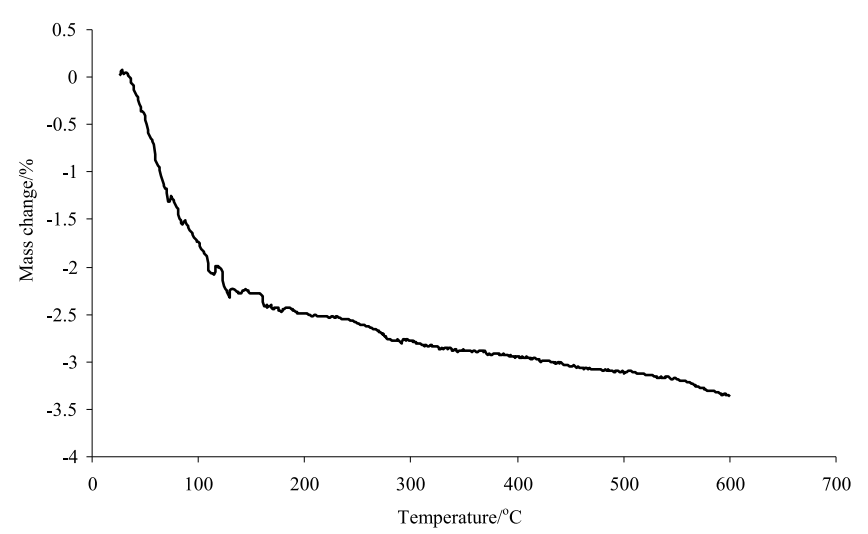

Figure 9. TG curve of pure zeolite determined by the thermogravimetric method

Figure 9 shows the TG line of pure zeolite. The sample mass is reduced during heating. The main weight loss can be seen up to $130^{\circ} \mathrm{C}$. Between this temperature and $600^{\circ} \mathrm{C}$, a further small decrease in sample mass is also observed. The result of DSC investigation (Figure 10) proved that in the initial period of sample heating there is an endothermic peak, which coincides with weight changes observed on the TG line (Figure 9). From the phase and elemental composition of the zeolite sample, it can be concluded that the observed process is probably related to the release of water associated with the zeolite structure. 


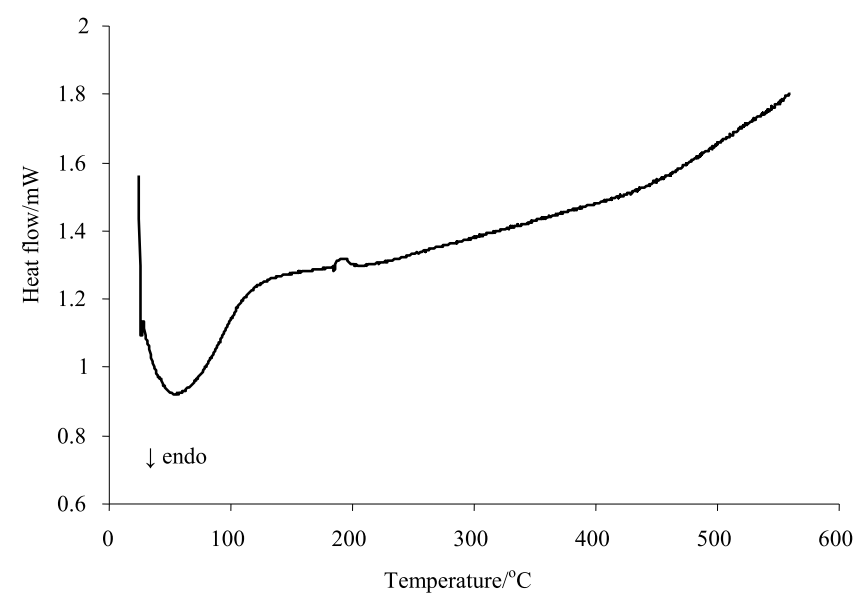

Figure 10. Differential scanning calorimetry (DSC) thermogram of pure zeolite sample

Similar investigations as for a pure zeolite were performed for samples of zeolite saturated with isopropanol. TG lines of zeolite samples with adsorbed isopropanol at $\mathrm{p} / \mathrm{p}^{0}-0.05,0.1$ and 0.8 are shown in Figure 11. With a change in temperature the weight of the sample decreased quite rapidly to about $250^{\circ} \mathrm{C}$. When the sample was heated further, the loss in mass was small. DSC measurement results of zeolite saturated with isopropanol are presented in Figure 12.

Comparison of this diagram (Figure 12) with the thermogram for pure zeolite (Figure 10), reveals that new peaks appear, which are associated with isopropanol desorption. The first peak occurs in the temperature

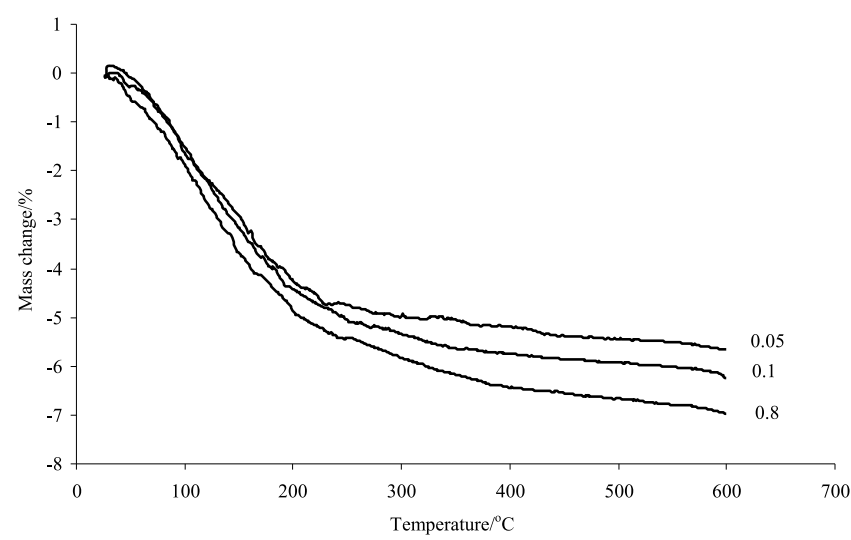

Figure 11. TG lines of zeolite samples saturated with isopropanol at $\mathrm{p} / \mathrm{p}^{0}-0.05,0.1$ and 0.8

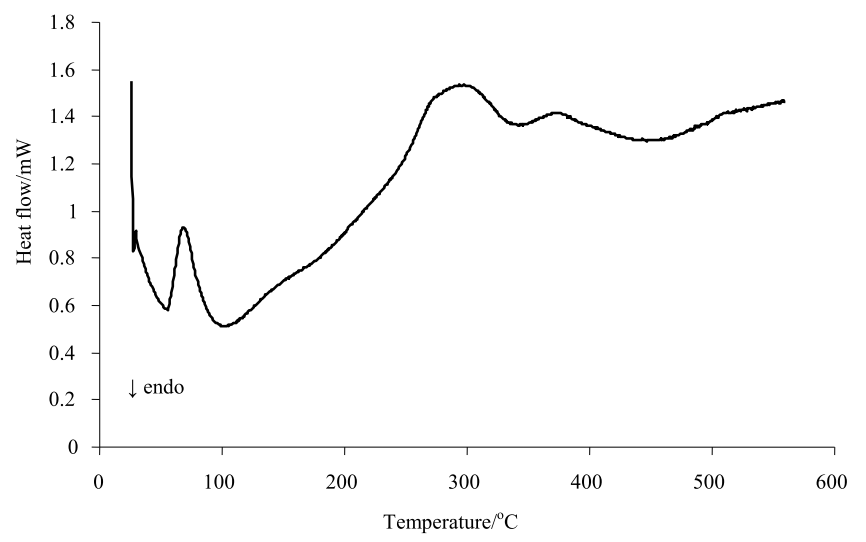

Figure 12. DSC thermogram of zeolite sample with absorbed isopropanol range from $50^{\circ} \mathrm{C}$ to $100^{\circ} \mathrm{C}$ and is probably related to the release of isopropanol adsorbed in a multilayer system. The relatively small amount of heat needed to desorb isopropanol at these temperatures can confirm the presence of this type of process. The next peak on the DSC curve occurs in the temperature range from $180^{\circ} \mathrm{C}$ to $450^{\circ} \mathrm{C}$. At these temperatures desorption of isopropanol adsorbed in the monolayer probably occurs. The temperature range of isopropanol desorption coincides with the range of mass changes on the TG curve. On this basis, it can be assumed that isopropanol in the monolayer is bound to the surface of the zeolite in the form of chemical bonds. The heat value of isopropanol desorption, estimated from DSC measurement, was 47.3 $\mathrm{kJ} / \mathrm{mol}$. This value is approximately consistent with the value of isopropanol adsorption enthalpy calculated on the basis of Huttig isotherm at $20^{\circ} \mathrm{C}$.

Table 4 presents the enthalpy values of isopropanol adsorption estimated on the basis of Langmuir and Huttig models in comparison with the values of desorption and condensation enthalpies. The results obtained are in the range of 43 to $50 \mathrm{~kJ} / \mathrm{mol}$. The exception is the enthalpy value estimated on the basis of the Langmuir model using the isotherm determined by the flow method. Such a significant deviation is most likely due to the shape of the isotherm indicating multilayer adsorption.

Table 4. Results of enthalpy calculations of isopropanol adsorption estimated on the basis of Langmuir and Huttig models in comparison with desorption and condensation enthalpies

\begin{tabular}{|l|c|}
\hline Models of calculations & $\begin{array}{c}\Delta \mathrm{H} \\
\left(\mathrm{kJ} \mathrm{mol}^{-1}\right)\end{array}$ \\
\hline Langmuir model, static method isotherm & -50.3 \\
\hline Huttig model, static method isotherm & -44.6 \\
\hline Langmuir model, flowing method isotherm & -70.1 \\
\hline Huttig model, flowing method isotherm & -43.0 \\
\hline Enthalpy of isopropanol condensation & -45.1 \\
\hline DSC measurement of isopropanol desorption & 47.3 \\
\hline
\end{tabular}

The presence of water in the carrier gas plays a very important role in the measurement of adsorption enthalpy. The presence of water can strongly interfere with the adsorption and desorption process of isopropanol. For this reason, the isotherm of water adsorption on zeolite was also investigated. The results of the investigation are presented in Figure 13. The water adsorption isotherm shows that within the initial concentration up to about $0.84 \mathrm{p} / \mathrm{p}^{0}$ the adsorption level is relatively low. With

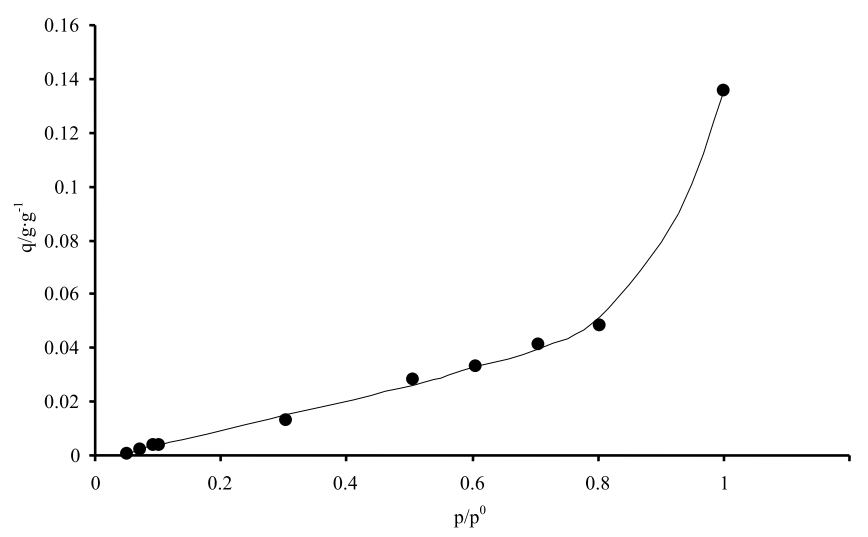

Figure 13. Isotherm of water adsorption on zeolite at $20^{\circ} \mathrm{C}$ determined by the flow method 
further increase in the concentration, the adsorption increases to a higher level at $\mathrm{p} / \mathrm{p}^{0}=1$. The shape of the water adsorption isotherm on the zeolite may indicate a weak interaction of water with the surface of the zeolite. For this reason, thermogravimetric and DSC calorimetry measurements of zeolite samples with adsorbed water were also performed. The results of thermogravimetric and DSC measurements are presented in Figure 14 and Figure 15, respectively.

Figure 14 presents the TG line of zeolite samples with adsorbed water, saturated at $\mathrm{p} / \mathrm{p}^{0}-0.09,0.3$ and 1 , respectively. The sample heating rate was $3 \mathrm{~K} /$ min. On the presented graph it is visible that with the change of temperature the mass loss of the sample to the temperature of about $130^{\circ} \mathrm{C}$ decreases quite rapidly. With further increase in temperature the loss in mass is slower and it can be noticed that over $200^{\circ} \mathrm{C}$ the further change in mass of the sample is small. This loss in mass coincides with the range of weight changes of a pure zeolite sample and may indicate that in case of a pure zeolite water is also released during sample heating. The shape of the TG line indicates that desorption of water from the zeolite surface does not require the use of high temperatures, and thus indicates a relatively weak relationship with the zeolite surface. DSC thermogram of a zeolite sample with adsorbed water (Figure 15) shows that in the initial stage of heating, an exothermic peak occurs, in the same temperature range in which the loss of sample mass on the TG curve is observed (Figure 14).

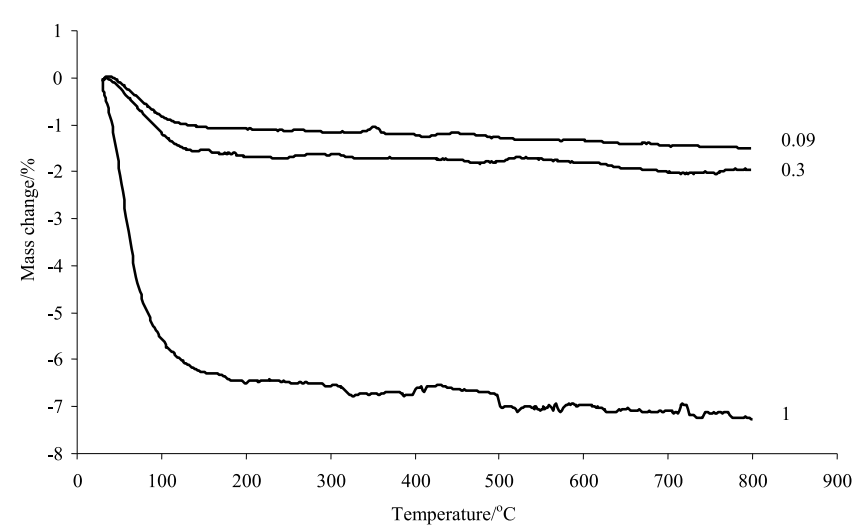

Figure 14. TG lines of zeolite samples with adsorbed water at $\mathrm{p} / \mathrm{p}^{0}-0.09,0.3$, and 1

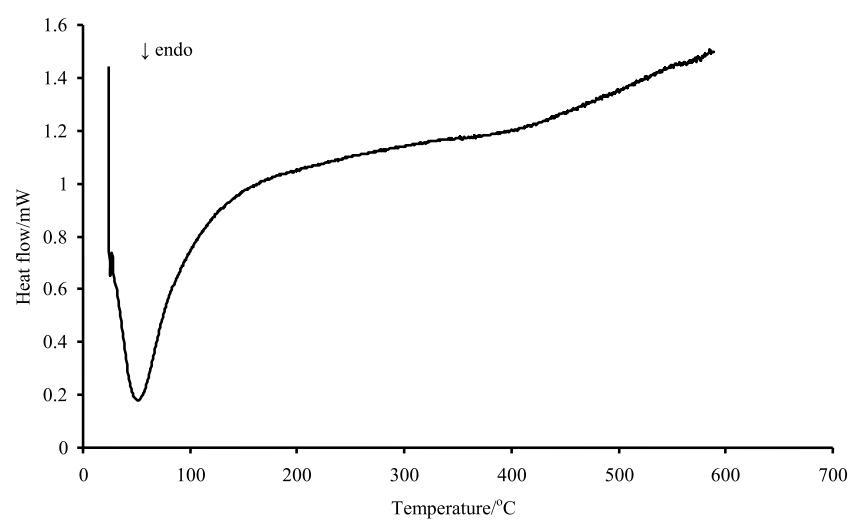

Figure 15. DSC thermogram of a zeolite sample with adsorbed water

\section{CONCLUSIONS}

Based on the determined adsorption isotherms, the adsorption enthalpy can be estimated, depending on the adsorption model used. The method of determination of adsorption isotherms, static or flowing, significantly influences on the calculated enthalpy values. In the case of the Langmuir model, the differences in the adsorption enthalpy values are quite large in comparison with the Huttig adsorption model, which better describes multilayered adsorption of isopropanol.

The estimated heat of isopropanol desorption from zeolite, based on the DSC measurement, was $47.3 \mathrm{~kJ} /$ mol. This value does not differ much from the adsorption enthalpy value estimated with the Huttig model for the adsorption isotherms determined both by static and flowing methods.

It was found that isotherms of isopropanol adsorption on zeolite at $20^{\circ} \mathrm{C}$ and $30^{\circ} \mathrm{C}$ obtained by the flow method belong to the II type, according to Brunauer classification. The shape of the adsorption isotherm measured by the static method is very similar to the classic Langmuir isotherm. In the case of adsorption isotherms measured by the flow method, their shape may indicate the phenomenon of capillary condensation. The isotherms measured by the flow method show slightly lower adsorption values compared with the results obtained by the static method.

From the phase and elemental composition tests of pure HiSiv 3000 zeolite, as well as TG and DSC tests, it was concluded that most likely the zeolite structure contains water associated with it. It was found that the weight loss of the zeolite sample with adsorbed water coincides with the range of changes in the weight of the pure zeolite sample, which confirms that water is released when the pure sample is heated.

The presence of water in the carrier gas plays a very important role in adsorption enthalpy measurements because it can strongly interfere with adsorption and desorption of compounds. The shape of water adsorption isotherm on HiSiv 3000 zeolite may indicate the weak interaction of water with the zeolite surface, which was confirmed by the desorption studies.

\section{LITERATURE CITED}

1. Arnaut L., Formosinho, S. \& Burrows, H. (2007). Chemical Kinetics, From Molecular Structure to Chemical Reactivity. pp. 251-272. Elsevier B.V.

2. Saha, D. \& Grappe, H.A. (2017). Adsorption properties of activated carbon fibers. Activated Carbon Fiber and Textiles, A volume in Woodhead Publishing Series in Textiles pp. 143-165 DOI:10.1016/B978-0-08-100660-3.00005-5.

3. Nastaj, J. \& Aleksandrzak, T. (2012). Comparison of static and dynamic methods of adsorption isotherms determination. 20th International Congress of Chemical and Process Engineering CHISA 2012 and the 15th Conference on Process Integration, Modelling and Optimisation for Energy Saving and Pollution Reduction PRES 2012 Prague, Czech Republic.

4. Downarowicz, D. (2015). Adsorption characteristics of propan-2-ol vapours on activated carbon Sorbonorit 4 in electrothermal temperature swing adsorption process. Adsorption. 21, 1-2, pp 87-98, DOI: 10.1007/s10450-015-9652-1.

5. Nastaj, J., Ambrożek, B., Witkiewicz, K. \& Rudnicka, J. (2016). Adsorption Isotherms of Propan-2-ol, Methylbenzene, and Tetrachloromethane on Selected Activated Carbons. J. 
Chem. \& Engin. Data, 61(10), 3559-3569, DOI: 10.1021/acs. jced.6b00488.

6. Prestianni, A., Cortese, R. \& Duca, D. (2013). Propan2-ol dehydration on H-ZSM-5 and H-Y zeolite: a DFT study. Reaction Kinetics, Mechanisms and Catalysis. 108(2), pp. 565-582. DOI: 10.1007/s11144-012-0522-5.

7. Chang, F.T., Lin, Y.C., Hsunling, B. \& Bau-Shei, P. (2003). Adsorption and desorption characteristics of semiconductor volatile organic compounds on the thermal swing honeycomb zeolite concentrator. J. Air \& Waste Manage. Assoc. 53(11), pp. 1384-1390.

8. Nastaj, J. \& Aleksandrzak, T. (2013). Adsorption Isotherms of Water, Propan-2-ol, and Methylbenzene Vapors on Grade 03 Silica Gel, Sorbonorit 4 Activated Carbon, and HiSiv 3000 Zeolite. J. Chem. Engine. Data, pp. 2629-2641, DOI:10.1021/je400517c.

9. UOP LLC advertising materials, Retrieved July 15, 2019, from https://www.chemia.ch/upload/files/pdf/gb\%20industrie/1445/PD_HiSiv3000.pdf

10. Bläker, Ch., Pasel, Ch., Luckas, M., Dreisbach, F. \& Bathen, D. (2017). Investigation of load-dependent heat of adsorption of alkanes and alkenes on zeolites and activated carbon, Microporous and Mesoporous Materials, 241, pp. 1-10, DOI: 10.1016/j.micromeso.2016.12.037.

11. Carlone, D., Rickard, B. \& Scaccia, A. (2010). Zeolite Catalyzed Ozonolysis, A Major Qualifying Project Proposal submitted to the Faculty and Staff of Worcester Polytechnic Institute for requirements to achieve the Degree of Bachelor of Science in Chemical Engineering.

12. Harlick, P.J.E. \& Teze, F.H. (2004). An experimental adsorbent screening study for $\mathrm{CO}_{2}$ removal from $\mathrm{N}_{2}$, Microporous and Mesoporous Materials. 76, (1-3), pp. 71-79, DOI: 10.1016/j.micromeso.2004.07.035.

13. Yaw's, C.L. (2009). Yaw's Handbook of Thermodynamic Properties for Hydrocarbons and Chemicals, Knovel, Retrieved July 15, 2019, from https://app.knovel.com/web/.

14. Jabłoński, M. \& Paderewski, M. (1981). Extension of the Huttig isotherm on mixed gas adsorption. Monatshefte fur Chemie, 112, pp. 533-536. 